\title{
Tool Effects on Hybrid Laminates Drilling
}

\author{
Luís Miguel Pereira Durão, João Manuel R. S. Tavares, Victor Hugo C. de Albuquerque, \\ António T. Marques, António G. Magalhães, and A. Aguiar Vieira
}

\begin{abstract}
Fiber reinforced plastics are increasing their importance as one of the most interesting groups of material on account of their low weight, high strength, and stiffness. To obtain good quality holes, it is important to identify the type of material, ply stacking sequence, and fiber orientation. In this article, the drilling of quasi-isotropic hybrid carbon+glass/epoxy plates is analyzed. Two commercial drills and a special step drill are compared considering the thrust force and delamination extension. Results suggest that the proposed step drill can be a suitable option in laminate drilling.
\end{abstract}

Keywords

Carbon fiber; Damage; Delamination; Drill geometry; Glass fiber; Image processing and analysis; Linear-elastic fracture mechanics; Thrust force.

\section{Introduction}

Composites are one of the most interesting groups of materials in our technological society. Their light weight and high strength characteristics make them suitable in applications where high stiffness and strength-to-weight ratio are desired. Hybrid composites combine effectively these characteristics with lower costs than monolithic materials.

Although composites are produced to near-net shape, machining is often needed, as it turns out necessary to fulfil requirements related with dimensional and geometrical tolerances or part assembly. Considering some adaptations, composites machining can be carried out using conventional machinery and tools. Among the several machining processes, drilling is one of the most frequently performed, for example, in the production of holes for screws, rivets, and bolts. However, drilling can cause several defects, like push-out delamination, intralaminar cracking, fiber/matrix debonding, and thermal damage, which can affect the load carrying capacity of laminated parts and their reliability [1]. Therefore, the production of higher quality holes with damage minimization is a key challenge for everyone involved in this industry. As some of the defects involved are not visible by visual inspection, it is needed to establish nondestructive testing (NDT) criteria in order to analyze their extension and severity.

The cutting process of a conventional conical point twist drill is unique and can be divided in two mechanisms: indentation by the drill chisel edge and orthogonal cutting by the major cutting edges of the tool. In a common drill, an indentation zone around the chisel can be identified. The region outside this zone, called secondary cutting edges area, is characterized by a negative rake angle. Along the cutting lips, the cutting action is a three-dimensional oblique cutting process. The cutting action is more efficient at the outer regions than near drill centre [2].

The importance of a dedicated drilling strategy or of a specific tool designed for the cutting of laminate composites has already been demonstrated [1,3-7]. Delamination is a problem that concerns all kinds of laminates. There are several published works concerning its reduction for glass fiber reinforced plastics, e.g., $[8,9]$, or [10] for a literature review on this theme.

In the most referred to analytical model, presented by Hocheng and Dharan [11], delamination mechanisms are assumed to be modelled by linear-elastic fracture mechanics (LEFM), considering the laminate structure of composites, its high elastic modulus, and the failure in delamination form. To avoid delamination damage onset and propagation, the applied thrust force should not surpass a critical load, which is a function of material properties and uncut thickness.

After laminate holes are drilled, it is important to establish criteria that can easily compare the delamination degree of the diverse processes. This comparison is only possible with the use of imaging acquisition techniques - as enhanced radiography or ultrasonic scanning - that returns an image of the damaged area of the laminate. However, it must be noted that such comparison is only valid when applied to composites with the same stacking sequence regarding orientation and number of plies.

Chen [12] proposed a comparing factor that enables the evaluation and analysis of delamination extension in laminated composites from the damaged areas. That ratio 
was called the delamination factor $\left(\mathrm{F}_{\mathrm{d}}\right)$, and it was defined as the ratio between the maximum delaminated diameter $\left(D_{\max }\right)$ and the hole nominal diameter (D):

$\mathrm{F}_{\mathrm{d}}=\mathrm{D}_{\max } / \mathrm{D}$.

This hole damage evaluation factor is based on the existence of damage images from C-Scan [12] or radiographs [13], and on the values of the damage areas obtained by counting manually the pixels of the associated areas or by using computational techniques of image processing and analysis $[14,15]$.

In this paper, hybrid plates made from carbon/epoxy and glass/epoxy prepreg with a stacking sequence of $\left[(0 /-45 / 90 / 45)_{\mathrm{C}} /(0 / 45 / 90 / 45)_{3 \mathrm{~V}}\right]_{\mathrm{s}}$, giving to the plate quasi-isotropic properties, are drilled using two types of commercially available drills, and the results are compared with an alternative drill design whose prototype was experimented.

Evaluation of tools is based on thrust force and delamination factor $\mathrm{F}_{\mathrm{d}}$. As already pointed out, three tool geometries were used: the first one is the common twist drill with a point angle of $118^{\circ}$ and a helix angle of $35^{\circ}$; another tool used is the Brad drill, initially developed for wood drilling, with an identical helix angle, but a different point design; the third and last tool considered is based on a suggestion of an alternative design proposed by $\mathrm{H}$. Dharan [16] in a Conference that was held in Porto about composites machining. Based on that suggestion, and on the step tool principle, a special step drill was designed, and a prototype was tested.

\section{Experimental work}

\section{Hybrid Laminates}

The term hybrid refers to a composite that has more than one type of matrix or fiber in its manufacture. The use of hybrid composites can expand the range of achievable properties when using composite materials and can be more cost-effective than conventional or advanced composites [17].

The scope of this work was a hybrid laminate using carbon and glass as reinforcement fibers. In this type of hybrid laminate, carbon fiber contributes with high tensile and compressive strength and stiffness, and reduces density while glass reduces final cost. This combination should be considered an excellent mix, as price and mechanical properties can be well balanced according to designer needs. A hybrid carbon/glass with only $25 \%$ of carbon increase both elastic and flexural modulus by $60 \%$ with a cost increase of approximately $5 \%$.

In order to elaborate the experimental procedure, it was necessary to define the percentage of carbon plies in the laminate and select one stacking sequence using carbon reinforced plies and glass reinforced plies. With such objective, ESACOMP ${ }^{@} 2.1$ package was used to simulate hybrid laminate properties and try to establish a cost effective material with enhanced properties. As the layup was supposed to be quasi-isotropic and the laminate thickness equal to $4 \mathrm{~mm}$, the number of plies and carbon proportion was set equal to $25 \%$. After the selection
Table 1.-Mechanical properties of hybrid laminates with ESACOMP ${ }^{@} 2.1$.

\begin{tabular}{lcccc}
\hline$\%$ of carbon reinforced plies & 0 (zero) & 25 & 50 & 75 \\
\hline Tensile strength [MPa] & 63.76 & 69.86 & 71.85 & 72.81 \\
Young's modulus [GPa] & 25.43 & 36.73 & 45.04 & 51.45 \\
\hline
\end{tabular}

of the percentage of carbon plies, it was necessary to evaluate the different options regarding the disposition of carbon and glass plies. Hence, several properties were considered, like tensile strength, Young's modulus and flexural modulus based on the prepreg properties available from the manufacturer's catalog. The results obtained for tensile strength and Young's modulus considering a quasiisotropic lay-up are indicated in Table 1. Flexural modulus is dependent on carbon plies distribution, as this has an influence on the final value. This comparison for $25 \%$ carbon reinforced plies can be seen in Fig. 1.

In accordance with ESACOMP ${ }^{\circledR}$ package results, it was decided to proceed with experimental work using the HIBC sequence only, that is to say, the one for which the outer plies of the laminate are reinforced with carbon fibers [Fig. 1(b)].

It was clear that the lay-up with carbon plies at the middle (HIBG) does not represent an advantage in flexural modulus when compared with plain glass (Table 1). Therefore, the correct choice of stacking sequence is also important in hybrids and should be made in accordance with the expected solicitations for the material in service. The other properties considered, tensile strength and Young's modulus, are not dependent on carbon plies distribution. A percentage of $25 \%$ of carbon fibers represents an expected increase of $10 \%$ in tensile strength and $45 \%$ in tensile modulus, when compared with glass/epoxy laminates.

\section{Materials and Drilling Tools}

The hybrid plates to perform the experimental work were made from carbon/epoxy and glass/epoxy prepreg with a stacking sequence of $\left[(0 /-45 / 90 / 45)_{\mathrm{C}} /(0 /-\right.$ $\left.45 / 90 / 45)_{3 \mathrm{~V}}\right]_{\mathrm{s}}$, giving the plate quasi-isotropic properties. The prepregs used were TEXIPREG@ HS 160 REM and TEXIPREG@ ET443 (SEAL, Italy). The laminate was then cured under $3 \mathrm{kPa}$ pressure and $140^{\circ} \mathrm{C}$ for one hour, using a hot plate press, and air cooled, as per manufacturer indication. At the end, and considering a ply thickness of $0.125 \mathrm{~mm}$, the plate final thickness was $4 \mathrm{~mm}$.

Plates were drilled in an OKUMA MC-40VA (Okuma, Japan) machining center, allowing the use of a large

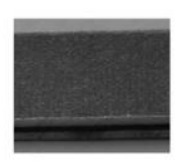

(a) $\mathrm{HIBG}-\mathrm{E}_{\mathrm{fl}}=26.64 \mathrm{GPa}$

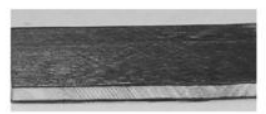

(b) $\mathrm{HIBC}-\mathrm{E}_{\mathrm{fl}}=31.91 \mathrm{GPa}$

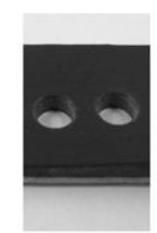

(c) Drilled HIBC plate
Figure 1.-From left to right, two examples of stacking sequences and drilled plate. 


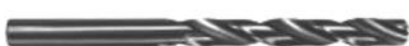

(a)

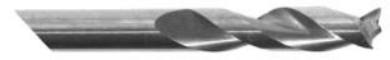

(b)

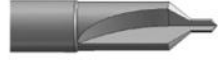

(c)

Figure 2.-Drills: a) twist; b) Brad; c) special step drill.

range of cutting speeds and feeds. Axial thrust force $\left(\mathrm{F}_{\mathrm{z}}\right)$ during drilling was monitored with a Kistler 4782 (Kistler, Switzerland) dynamometer associated to a multichannel amplifier and data acquisition for a desktop computer. The workpiece was clamped to the dynamometer prior to drilling.

The parts were drilled without the use of a sacrificial plate. All the drills have a diameter of $6 \mathrm{~mm}$ and were made in tungsten carbide (Fig. 2). Twist drill (Fig. 2a) is a tool with a standard geometry and associated with its use a pilot hole of $1.1 \mathrm{~mm}$ diameter was performed. The intention of the pilot hole was to reduce the maximum thrust force and decrease delamination around the hole by cancelling the chisel edge effect of the drill. Brad drill (Fig. 2b) is a special drill, originally designed for wood drilling, with edges in scythe shape, that cause the tensioning of the fibers prior to cut, thus enabling a "clean cut" and a smooth machined surface.

Finally, an alternative drill design was developed and experimented. During a lecture in INEGI-Porto in 2000, $\mathrm{H}$. Dharan had suggested a step geometry for a new drill design [16]. The special step drill (Fig. 2c) has two drilling diameters, 1.25 and $6 \mathrm{~mm}$, dividing the drilling operation, and consequently, the thrust force, in two stages. This division of the drilling operation also cancels the chisel edge effect for the final hole diameter drilling. To accomplish a smooth transition, the diameter change has a conical shape. The reduction of delamination risk by reducing the maximum thrust force is also looked for. Another advantage of this tool is the possibility of performing the hole in just one operation. This represents a gain in operation time when compared with the use of a pilot hole, since there is no need to undergo a tool changing operation. The drill tip was designed in a way to promote the initiation of the cutting action immediately after touching the plate, thus reducing the indentation effect.

After a certain number of experimental drillings, cutting parameters selected were two feed rates, 0.025 and $0.050 \mathrm{~mm} / \mathrm{rev}$, and a cutting speed, $53 \mathrm{~m} / \mathrm{min}$, corresponding to a spindle speed of $2800 \mathrm{rpm}$. This speed is usual in vertical drilling machines, even with discrete regulation only. The use of higher feeds has caused peel-up delamination, a kind of damage that is likely to happen when the drill tip touches the upper plies of the laminate.

All results indicated in this paper represent the average of five tests performed under the same conditions. As there is a signal variation during one drill rotation due to the mechanics of the process itself, the thrust force was always averaged over one spindle revolution. The results of this average will be referred to as thrust force.

\section{Results and discussion}

\section{Thrust Force}

The development of axial thrust force during drilling operation follows a typical curve (Fig. 3). At the beginning, there is a rise of the force values, corresponding to the contact between drill tip and part. As the drill contact diameter increases from chisel size to its nominal value, there is a quick rise of the thrust force. This increase becomes reasonably steady during a period of normal drilling with the drill cutting the material at nominal diameter. This period has a duration corresponding to the perforation of all the plate thickness. As the drill tip reaches the exit side of the plate, the thrust force decreases rapidly towards zero.

When compared with those obtained with twist or Brad drills, the force-displacement curve for the alternative drill has a different shape, Fig. 3. The main reason for that difference comes from the drill geometry joining the two steps, pilot and final hole, in one action only. The two phases of the drilling are well distinguishable in a graph. After a rise of the force when the drill touches the plate, the stabilization occurs at a lower level of force, below $20 \mathrm{~N}$, corresponding to the first diameter full engagement. When the drill tip reaches the bottom of the plate, thrust force starts to descend but without reaching zero. That is the moment when the second conical region of the drill starts to contact the top of the plate causing the force to increase again, but avoiding a sum of the two effects, by the correct selection of the drill tip length, slightly superior to the plate thickness. The second part of the thrust-displacement curve is more similar to those observed effects when using twist drill.

The result that has been considered for comparison was the maximum thrust force during drilling. As all the plates were of the same thickness, as well as the cutting parameters, the only difference in the thrust force values

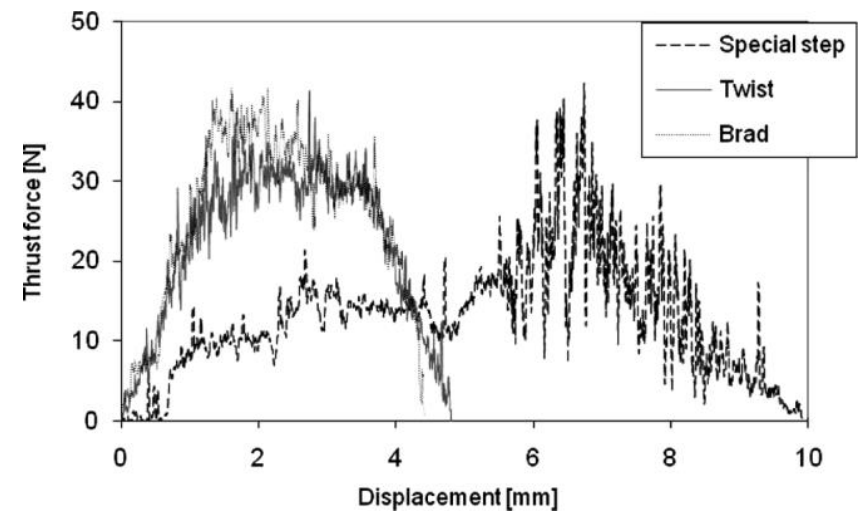

Figure 3.-Comparison of the thrust-displacement curves for the three drill geometries. 
Table 2.- Summary of results for the three drills compared.

\begin{tabular}{lcccccc}
\hline & \multicolumn{2}{c}{ Special step drill } & \multicolumn{2}{c}{ Twist drill } & \multicolumn{2}{c}{ Brad drill } \\
\hline Feed [mm/rev] & 0.025 & 0.05 & 0.025 & 0.05 & 0.025 & 0.05 \\
Max thrust force [N] & 42.7 & 70.4 & 41.3 & 75.0 & 42.1 & 57.5 \\
Delamination factor $\left(\mathrm{F}_{\mathrm{d}}\right)$ & 1.05 & 1.13 & 1.08 & 1.18 & 1.09 & 1.11 \\
\hline
\end{tabular}

comes from the different geometries of the drills. This is a first indication about the likeliness of delamination onset, as the occurrence of this damage is normally related with the axial thrust force that acts over the uncut plies of the laminate. In Table 2, a comparison of results for a cutting speed of $53 \mathrm{~m} / \mathrm{min}$ and two different feeds used, 0.025 and $0.05 \mathrm{~mm} / \mathrm{rev}$, when drilling hybrid plates is presented.

For the lower value of feed rate, the maximum thrust force values are almost identical for the three drills considered. The difference between the Brad drill and the other two drills is more evident when a feed rate of $0.05 \mathrm{~mm} / \mathrm{rev}$ was considered, see Fig. 4. Under the higher feed rate, the Brad

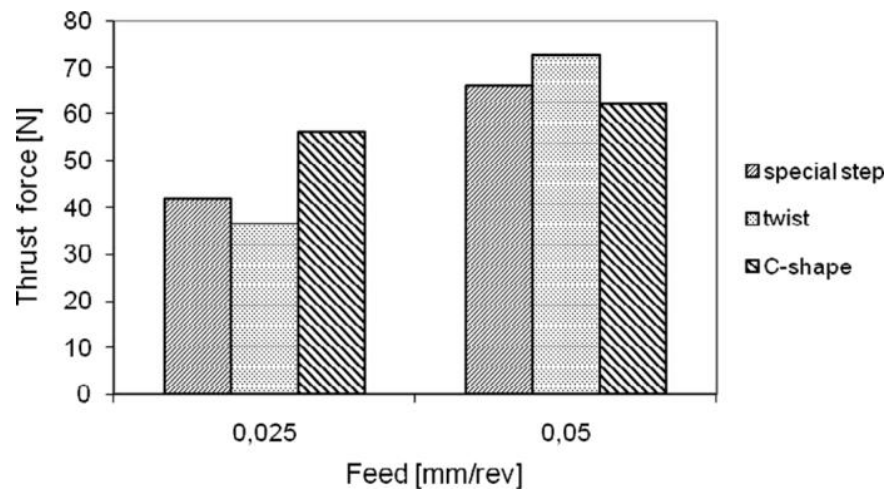

Figure 4.-Comparison of maximum thrust forces for the three drill geometries. drill has the lowest maximum value of thrust force. For the other tools, results are again similar. This indicates that the result of a pilot hole is identical to the effect of the new tool and that is the canceling of the chisel edge effect on laminate drilling. One has to remember that the diameter of the pilot hole selected for this work, $1.1 \mathrm{~mm}$, the first diameter of the new tool, $1.26 \mathrm{~mm}$, and the chisel edge dimension of the twist drill, $1.08 \mathrm{~mm}$, are within the same range. So, this result is not to be seen as surprising. In fact, the selection of the pilot hole and the first diameter of the special tool were made in accordance with the known length of the twist drill chisel edge.

Another point that deserves attention is the fact that the increase in feed rate has caused an increase for the maximum thrust force for all the drills. It is known that feed rate has a direct effect on thrust force during drilling.

\section{Delamination Measurement}

As plates are opaque, a simple visual inspection is not able to detect internal damages, like delamination or others. For this reason, the use of imaging acquisition techniques, like enhanced radiography, ultrasonic scanning or computerized tomography, becomes essential when there is a need for non destructive inspection.

Radiography is suitable for the detection of delaminations only if a contrasting fluid is used. Therefore, the process is known as enhanced radiography. With such purpose, di-iodomethane- $-\mathrm{CH}_{2} \mathrm{I}_{2}$, methylene iodide-was used. This product is radio-opaque, which is the important characteristic for the objective of its use.

To obtain the radiographic images to be analyzed, plates were immersed in di-iodomethane for one and a half hour in a dark chamber. After time elapsed, plates were carefully cleaned and radiographed. Developed films were used for the measurement of delamination around the holes with the help of computational techniques of image processing and analysis. The use of those techniques has

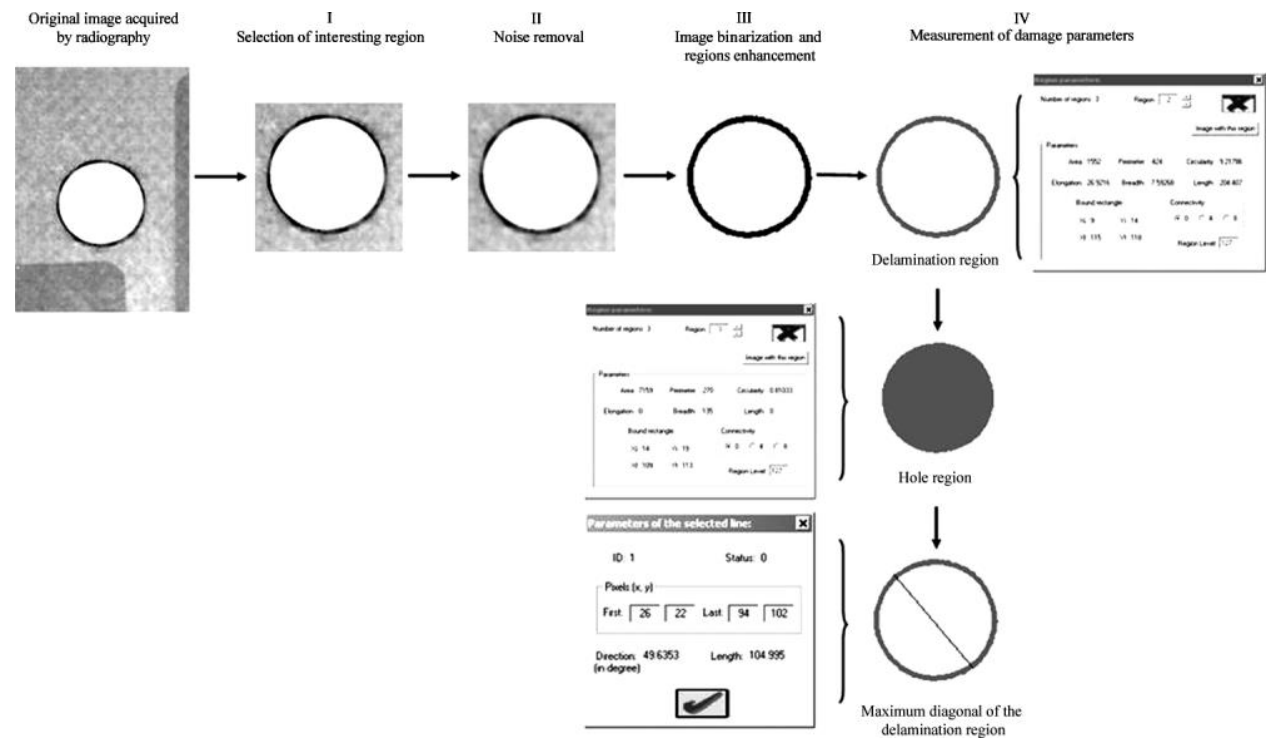

Figure 5.-Pipeline of the analysis of an image acquired by radiography using the adopted computational platform [18, 19]. 


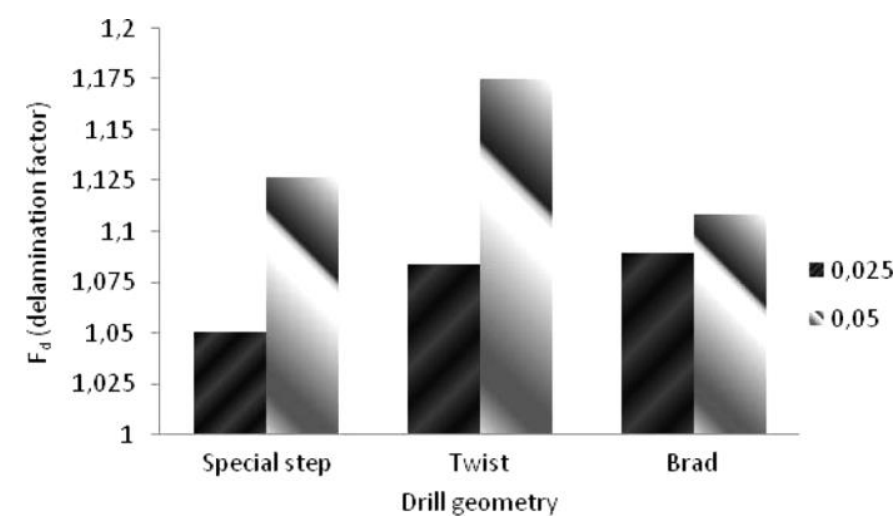

Figure 6.-Delamination factor $\left(\mathrm{F}_{\mathrm{d}}\right)$ for the three drill geometries and two feed rates.

the purpose to achieve robust and accurate information on the damaged areas from the images acquired by radiography. Additionally, this process has the advantage of reducing operator's subjectivity, thus increasing the results' reliability.

An existing processing and image analysis platform was used $[18,19]$, which turned possible the use of some standard Computational Vision techniques [20-22] to achieve the required values, Fig. 5.

Results achieved by the procedure described are shown in Fig. 6 for the two feed rates considered, 0.025 and $0.50 \mathrm{~mm} / \mathrm{rev}$. Delamination factor was calculated using Eq. (1), with the maximum delaminated diameter obtained from the images acquired by radiography and assuming a hole diameter of $6 \mathrm{~mm}$.

Observing the results in Fig. 6 and Table 2, it is possible to verify that the effect of feed rate increase is not equivalent in the three drill geometries considered. The Brad drill seems to be less affected by this variation as the delamination factor does not change so much as for the other drills. Consequently, Brad drilled plates that had the worst result for the lowest feed, becomes the less delaminated ones when the highest feed is concerned. Additionally, delamination caused by twist drill with highest feed rate has remarkably increased. This drill appears to be more affected by the increase of feed rate, in terms of plate damage. The new drill has interesting results. For the lowest feed, the delaminated diameter has the best rate and for the highest feed, although the value of the delamination factor has increased, it keeps close to the best value found for Brad drill. It should be noted that the specific geometry of this drill, cancelling the chisel edge but doing the pilot and the final hole in one operation only needs to have a diameter transition zone. That zone, with an angle of $118^{\circ}$ - similar to twist drill point angle - may need optimization in order to reduce machining damage machining.

\section{Conclusions}

Three different tools for drilling hybrid laminates were compared, one of them being a prototype design for a specific tool for this kind of materials, and the others the twist drill with a pilot hole and a Brad drill. With that purpose, a laminate with two types of reinforcement carbon and glass - fibers in an epoxy matrix was drilled using the three drills. Feed rate was also included as an experimental factor, by adopting two different values.

Results have shown that feed rate is an important factor in thrust force and delamination. As cutting speed was not considered as a factor in this study, its influence was not analyzed. The use of adequate drill geometry has also a distinct effect on the outcome for the two results considered for damage evaluation.

In Table 2, a summary of the results from experimental work is presented. Comparing the results for the three drills, it can be said that the proposed special step tool does not show a definitive advantage on commercial available tools. The results of thrust force are similar although the delamination is smaller only when lower feed was used. Development work on this tool concept should be carried on. The design of this tool allows for the cancelling of the chisel edge effect, usually considered as the main responsible for delamination onset when laminate plates are drilled. The other advantage of this tool resides in the reduction of drilling operating time as it is not necessary to change tools between the pilot hole and final hole.

The basic design of the proposed tool seems to deserve the time needed for development, according to the results here presented and that should be confirmed with additional testing and parameter optimization for several kinds of laminates with different reinforcements.

\section{Acknowledgments}

Authors wish to acknowledge the Portuguese Fundação para a Ciência e Tecnologia (FCT) for supporting the work here presented under project PTDC/EMETME/66207/2006.

\section{References}

1. Persson, E.; Eriksson, I.; Zackrisson, L. Effects of hole machining defects on strength and fatigue life of composite laminates. Composites A 1997, 28, 141-151.

2. Langella, A.; Nele, L.; Maio, A. A torque and thrust prediction model for drilling of composite materials. Composites A 2005, $36,83-93$.

3. Piquet, R.; Ferret, B.; Lachaud, F.; Swider, P. Experimental analysis of drilling damage in thin carbon/epoxy plate using special drills. Composites A 2000, 31, 1107-1115.

4. Tsao, C.C.; Hocheng, H. Taguchi analysis of delamination associated with various drill bits in drilling of composite material. Int. J. Machine Tools and Manufacture 2004, 44, 1085-1090.

5. Hocheng, H.; Tsao, C.C. Effects of special drill bits on drillinginduced delamination of composite materials. Int. J. Machine Tools and Manufacture 2006, 46, 1403-1416.

6. Tsao, C.C.; Hocheng, H. Parametric study on thrust force of core drill. J. Materials Processing Technology 2007, 192-193, 37-40.

7. Fernandes, M.; Cook, C. Drilling of carbon composites using a one shot drill bit. Part II: Empirical modelling of maximum thrust force. Int. J. Machine Tools and Manufacture 2006, 46, 76-79.

8. Singh, I.; Bhatnagar, N.; Viswanath, J. Drilling of uni-directional glass fiber reinforced plastics: Experimental and finite element study. Materials and Design 2008, 29, 546-553. 
9. Rubio, J.C.; Abrão, A.M.; Faria, P.E.; Correia, A.E.; Davim, J.P. Effects of high speed in the drilling of glass fibre reinforced plastic: Evaluation of the delamination factor. Int. J. Machine Tools and Manufacture 2008, 48, 715-720.

10. Abrão, A.M.; Faria, P.E.; Rubio, J.C.; Reis, P.; Davim, J.P. Drilling of fiber reinforced plastics: A review. J. Materials Processing Technology 2007, 186, 1-7.

11. Hocheng, H.; Dharan, C.K.H. Delamination during drilling in composite laminates. J. Engineering for Industry 1990, 112, 236239.

12. Chen, W.C. Some experimental investigations in the drilling of carbon fibre-reinforced plastic (CFRP) composite laminates. Int. J. Machine Tools and Manufacture 1997, 37, 1097-1108.

13. Mehta, M.; Reinhart, T.J.; Soni, A.H. Effect of fastener hole drilling anomalies on structural integrity of PMR-15/Gr composite laminates. Proc. of the Machining Composite Materials Symposium, ASM Materials Week 1992, 113-126.

14. Davim, J.P.; Rubio, J.C.; Abrão, A.M. A novel approach based on digital image analysis to evaluate the delamination factor after drilling composite laminates. Composites Science and Technology 2007, 67, 1939-1945.
15. Durão, L.M.P.; Tavares, J.M.R.S.; Marques, A.T.; Baptista, A.M.; Magalhães, A.G. Damage analysis of carbon/epoxy plates after drilling. Int. Journal of Materials and Product Technology 2008, 32, 226-242.

16. Dharan, C.K.H. Composites machining, future perspectives in composites materials. INEGI, Porto, October 2000.

17. Schwartz, M.M. Composite Materials Handbook; McGraw-Hill: New York, 1988.

18. Tavares, J.M.R.S. Análise de Movimento de Corpos Deformáveis usando Visão Computacional. Ph.D. thesis, FEUP Porto, 2000 (in Portuguese).

19. Tavares, J.M.R.S.; Barbosa, J.G.; Padilha, A.J. Apresentação de um Banco de Desenvolvimento e Ensaio para Objectos Deformáveis, RESI-Revista Electrónica de Sistemas de Informação 2002, 2, 14 p. (in Portuguese).

20. Awcock, G.W.; Thomas, R. Applied Image Processing; McGrawHill International Editions: New York, 1995.

21. Jain, R.; Kasturi, R.; Schunck, B.G. Machine Vision; McGrawHill International Editions: New York, 1995.

22. Schalkoff, R.J. Digital Image Processing and Computer Vision; John Willey \& Sons, Inc.: New York, 1989. 